\title{
The Lived Experience of Smoking in Pregnancy
}

\author{
Cynthia L. Murray ${ }^{*}$, Sandra P. Small1, Lorraine Burrage ${ }^{2}$ \\ ${ }^{1}$ School of Nursing, Memorial University of Newfoundland, St. John's, Canada \\ ${ }^{2}$ Newfoundland and Labrador Provincial Perinatal Program, St. John's, Canada \\ Email: ${ }^{*}$ cindym@mun.ca
}

Received 17 June 2014; revised 21 August 2014; accepted 15 October 2014

Copyright (C) 2014 by authors and Scientific Research Publishing Inc.

This work is licensed under the Creative Commons Attribution International License (CC BY). http://creativecommons.org/licenses/by/4.0/

(c) (i) Open Access

\begin{abstract}
Smoking in pregnancy is associated with adverse pregnancy outcomes, such as low birth weight, preterm birth, and perinatal death. Despite widespread public awareness of the deleterious health effects of cigarette smoking, up to a quarter of women in developed countries smoke during their pregnancies. In this hermeneutic phenomenological study, the meaning and experience of smoking in pregnancy were explored. Data were collected through interviews with eight pregnant women from the Canadian province of Newfoundland and Labrador. Four main themes were identified in the participants' stories, namely living in a smoking world, suddenly finding myself on a moral low road, navigating my own way to a high road, and not preparing for postpartum smoking pitfalls. Smoking was perceived to be salubrious and the participants painted a picture of dealing with smoking in pregnancy as a daunting, lonely endeavor that required life-altering solutions. With a better understanding of what smoking means to pregnant women who smoke, nurses can help these women forge a new and lifelong way to health and wellness.
\end{abstract}

\section{Keywords}

Addiction, Substance Use, Hermeneutic Phenomenology, Lived Experience, Pregnancy, Tobacco Smoking Cessation

\section{Introduction}

Cigarette smoking in pregnancy is an important, preventable behavior associated with low birth weight, preterm birth, and perinatal death [1]. Gestational smoking has also been implicated as a concomitant factor in childhood obesity [2], asthma [3], recurrent lower respiratory tract infections [4], otitis media [5], sudden infant death, behavioral problems, neurocognitive deficits, and adolescent smoking [6].

"Corresponding author. 
Despite an abundance of smoking prevention and cessation interventions, as well as widespread public knowledge of the risks of smoking, maternal smoking is a substantial, global public health problem. Estimates of gestational smoking range between $6 \%$ and $22 \%$ in high-income countries, but the burden of smoking in pregnancy is starting to shift from high-income nations to low- and middle-income nations [1] [7]. Within developed countries, prevalence rates of gestational smoking have plateaued and remained high among socially disadvantaged groups, such as indigenous and low-income populations [6]. For example, in Canada, 11\% of pregnant women report smoking, but the number climbs to $20 \%$ among low-income women [8] and soars to $61 \%-82 \%$ for Aboriginal women [9]-[11]. Furthermore, researchers availing of serum cotinine levels have shown that $23 \%$ to $28 \%$ of pregnant smokers do not report their tobacco use due to the stigma attached to the behavior [12]. Therefore, the true prevalence of gestational smoking may be higher in spite of extensive efforts to curtail smoking.

Although a plethora of studies have been conducted on the prevalence, etiology, pathophysiology, prevention, and treatment of gestational smoking, relatively few studies have taken a qualitative approach to examining the problem. Within the realm of qualitative research in this substantive area, some studies were carried out more than 20 years ago [13] [14] and others focused solely on specific populations, namely adolescents [15] and lowincome women [16]-[18]. In addition, several researchers examined aspects of the experience of smoking in pregnancy, such as pregnant smokers' views on prenatal smoking cessation interventions [19]-[21], attempts at quitting, knowledge and concerns about health risks associated with gestational smoking [22], and smokingrelated stigma [23]. Another qualitative inquiry involved a retrospective exploration of gestational smoking 2 to 3 years post-pregnancy [24].

A literature search of 10 databases (i.e., PubMed, Cochrane Library, MEDLINE, CINAHL, EMBASE, Web of Science, Scopus, Sociological Abstracts, PsycINFO, and ERIC) for English language studies carried out in the last 20 years, using the keywords pregnancy or gestation and smoking, only yielded one qualitative study that investigated pregnant women's entire experience of smoking [25]. The study revealed three major themes: pregnancy as a context for stopping smoking; returning to smoking; and social pressures on smoking behavior. One phenomenographic study was also found, which focused specifically on variation in the way pregnant women make sense of smoking during pregnancy [26]. Five different ways in which pregnant women were making sense of gestational smoking were discerned: smoking can be justified; will stop later; my smoking might hurt the baby; smoking is just given up; and smoking must be taken charge of. Neither study used a hermeneutic phenomenological approach, which examines in-depth the hidden meaning of the whole experience. Therefore, the purpose of the current hermeneutic phenomenological study was to explore the meaning and the totality of the lived experience of smoking in pregnancy.

\section{Methods}

vanManen's [27] approach to hermeneutic phenomenology was used to guide this study. Hermeneutic phenomenologists seek to understand the meaning of everyday experiences [27], which produces practical knowledge and promotes reflective practice [28]. In keeping with hermeneutic phenomenological methodology, the research question for this study was: What is the meaning and experience of cigarette smoking for pregnant women?

\subsection{Setting}

The study was conducted in the province of Newfoundland and Labrador (NL), Canada. The provincial rate of gestational smoking hovers around 10.6\% [8] [29], but it is higher in central and north east Labrador (i.e., 44\% 53\%) where the majority of Aboriginal people smoke [30]-[32]. Among the members of Healthy Baby Clubs, which provide services to socioeconomically disadvantaged pregnant and postpartum women in NL, $43 \%$ report gestational smoking and of these women, only 26\% quit smoking during pregnancy [31]. Smoking in pregnancy was recently in the provincial news because it was identified by the Alliance for the Control of Tobacco in NL as a priority area [33].

\subsection{Recruitment and Participants}

The study sample consisted of eight pregnant women, who smoked during their current pregnancies. To examine the experience in-depth, Morse and Field [34] recommend a sample size of about 6 - 10 participants for pheno- 
menological studies. The inclusion criteria specified that a participant must be a pregnant emancipated minor or woman, 19 years of age or older, who smoked or quit smoking during her pregnancy. Obstetricians in the region were contacted to seek their assistance in recruiting participants. The obstetricians were instructed to display posters about the study in their waiting and examination rooms and give those who met the inclusion criteria a pamphlet about it. The onus was on the women to contact the first author at the given phone number or email address on the printed recruitment materials. Also, study posters and pamphlets were distributed to the Healthy Baby Clubs throughout the area. While two of the women learned about the study via obstetricians, six were recruited through the Healthy Baby Clubs. When contacted by a potential participant, the first author explained the study and ensured that self-referred participants met the inclusion criteria. Interviews were arranged with those who expressed an interest in participating.

The mean age of the women in this study was 23.8 years ( $\mathrm{SD}=3.9$ years), with a range of 20 to 31 years. Of the eight women, six had gross annual household incomes less than \$20,000 Canadian and two fell between $\$ 30,000$ and $\$ 50,000$. With four exceptions, the women had at least some university or college education. One participant graduated from high school, but had no post-secondary education. Three women dropped out of high school. Apart from three stay-at-home mothers and one individual who was unemployed, the women worked. Two individuals were employed full-time and one person worked part-time in the service industry, while another woman held a full-time job in management. All of the women were White and most of the women $(n=5)$ were married or lived in a common-law relationship. Three of the women were single and had no partner. With only one exception, all of the partners smoked. More than half $(n=5)$ of the participants were primiparous and three were multiparous. None of the pregnancies were planned and the interviews were completed when the women were between 12 and 33 weeks of gestation. Prior to their pregnancies, two women smoked a pack of cigarettes over a period of 3 days and the remaining participants smoked a pack per day. All but one person started smoking between the ages of 11 and 15 . The average duration of smoking was 9.8 years ( $S D=5.2$ years), with a range of 3 to 17 years. In their stories, four of the women divulged illicit drug use in the past. Two participants were currently enrolled in a local methadone maintenance treatment program. At the time of the study, three of the eight women quit smoking cigarettes. The remaining five women were trying to cut back on their smoking as much as possible, with four women going from a pack to 5 - 10 cigarettes daily and one woman currently smoking either her usual, pre-pregnancy pack of cigarettes per day or a "little" less.

\subsection{Ethical Considerations}

Ethical approval for the study was received from the Human Investigation Committee at Memorial University of Newfoundland prior to the commencement of the study. Written informed consent, which included permission to audio record the interview, was obtained by the first author before beginning each interview. During the consent process, the participants were told that a second interview might be requested if the researchers needed to clarify or further explore their thoughts and feelings. In addition, it was pointed out to the pregnant women that some individuals might find it upsetting to talk about their experiences and perceptions of smoking during pregnancy. Every participant was informed that she could decline to answer any question, stop the interview, and/or withdraw from the study at any time, with no penalty. During the course of the study, no participant indicated verbally or nonverbally any signs of discomfort or distress in talking about her experience with gestational smoking. Every interview was conducted in private at a time and place that was chosen by the participant. Two interviews were held in the participants' homes, whereas the other interviews took place in the researcher's office. All of the pregnant women received a $\$ 30$ grocery gift certificate as a token of appreciation for their participation.

\subsection{Data Collection}

One face-to-face interview with each participant was used to collect data in the study. The first author conducted all of the interviews. During the interviews, each woman was asked to talk about her experience of smoking in pregnancy. To obtain the participant's unfettered story, the researcher asked open-ended questions, such as "Could you please tell me a story about what it is like to smoke during pregnancy?" and "Could you please tell me a story about someone commenting on smoking in pregnancy?” If necessary, to glean more details about the experience, the researcher used probes, such as "How did you feel about that?" and "Could you tell me more about that?” In hermeneutic phenomenology, the interviews are best described as hermeneutic conversations or 
discussions [27]. Although an interview guide with possible questions was designed specifically for this study, the interviews were informal, flexible conversations with spontaneous questions that allowed the participants to respond in an extended manner. Sociodemographic information, such as age and level of education, were collected at the end of the interview to describe the sample and to help interpret the data. Each interview took 60 to 90 minutes to complete. Participant recruitment and data collection ceased when a good phenomenological gestalt in the text was obtained [35] and no new information was forthcoming from the interviews.

\subsection{Data Analysis and Rigor}

The data analysis was interwoven with data collection and it was informed by van Manen's [27] approach, which includes six research activities: (a) turning to the nature of lived experience; (b) investigating experience as we live it; (c) reflecting on essential themes; (d) writing and rewriting; (e) maintaining a strong and oriented relation; and (f) balancing the research context by considering parts and whole. Although the activities might appear to be a linear process, there is a nonlinear, dynamic interplay between all of the activities [27].

Our research team consisted of two experienced phenomenological researchers (C.M. and S.S.), one member with extensive experience and expertise in perinatal health care (L.B.), and one member with substantial research and professional experience in the areas of respiratory health and illness, smoking, and smoking cessation (S.S.). The audio-recorded interviews were transcribed verbatim into written text. The transcripts were read multiple times and reflected upon by each researcher independently. In hermeneutic conversations, participants also reflect on their experiences and the interviewer and interviewee collaborate on interpreting the significance or meaning of these experiences [27]. Consequently, the first author identified some tentative themes in conjunction with the participants. Further theme development was accomplished by the first author through van Manen's [27] six interrelated research activities. For example, the researcher used van Manen's selective approach and the four existentials (i.e., lived body, lived time, lived space, and lived human relation) to reflect on and analyze the transcripts. Moreover, the researcher dialectically considered parts of the text and the larger context provided by the whole text. Provisional themes were discussed and refined by the first two authors and the finalized themes were agreed on by all of the researchers.

Throughout the research process, we used the following verification strategies for establishing reliability and validity in qualitative research: investigator responsiveness, methodological coherence, concurrent data collection and analysis, and sampling sufficiency [36] [37]. We set aside or bracketed the knowledge we garnered from our clinical experience and literature review on gestational smoking [36]. This helped us to stay open and listen to the women's stories without imposing preconceived ideas on the data. The research question, method, and data and analytic procedures were consistent with van Manen's [27] hermeneutic phenomenological approach. We kept an audit trail so that other researchers could follow the entire research process. The data collection and analysis occurred simultaneously. We continued to collect data until there was a gestalt in the text and redundancy in the interviews. Furthermore, we independently ensured that the themes fit with the data.

\section{Results}

We identified 4 main themes (i.e., living in a smoking world, suddenly finding myself on a moral low road, navigating my own way to a high road, and not preparing for postpartum smoking pitfalls) and 11 subthemes in the women's stories of smoking in pregnancy (see Table 1). Pseudonyms are used as each main theme and accompanying subthemes are discussed.

\subsection{Living in a Smoking World}

Two subthemes were subsumed into the theme of living in a smoking world: (a) being immersed in a smoking world; and (b) obtaining salubrious effects from smoking. Living in a smoking world was at the core or essence of the experience because all of the other themes stemmed from it.

Being Immersed in a Smoking World. While recounting their stories, the women revealed information about their background or "situatedness" in the world [27] (p. 101). It was evident that all of the women's lives were steeped in smoking. The women were surrounded by a large circle of smoking family members and/or friends. Some of the participants remarked about a cycle of smoking within families. In her statements below, Jennifer shared her belief that smoking ran in families and that it was a matter of fate or destiny: 
Table 1. Themes and subthemes identified in the participants' stories of smoking in pregnancy.

\begin{tabular}{cc}
\hline \multicolumn{1}{c}{ Theme } & Subtheme \\
\hline Living in a smoking world & $\begin{array}{c}\text { Being immersed in a smoking world } \\
\text { Obtaining salubrious effects from smoking }\end{array}$ \\
Becoming unexpectedly pregnant \\
Suddenly finding myself on a moral low road & Smoking on autopilot \\
Navigating my own way to a high road & Being subjected to judgment and condemnation \\
Suffering emotionally \\
Being left to my own devices \\
Encountering roadblocks to quitting \\
Aiming for a high road by cutting down or quitting \\
Being informed about postpartum smoking pitfalls \\
Taking a wait-and-see approach
\end{tabular}

Everybody these days [who smokes] ...somebody along their line [smoked]. Either their parents smoked, their grandparents smoked, or their aunts or uncles smoked, or their cousins smoked or whatever. It's all in the family no matter what way you look at it.

If my son or daughter comes home and says, "I’m smoking.” It's like, “...[Well,] I can’t stop ya. I smoked when I was your age. Your father did. You got it off us and that's all I can do.” ...I wish I could have stopped it from happening when I was 11. I probably wish I could have started when I was 16 or 17.... I shouldn't have started that day, but somehow, someway, somebody is going to start.

At the beginning of their pregnancies, smoking was firmly entrenched in their everyday lives. All of the women discussed at length a number of activities (e.g., relaxing, taking a break from work, socializing, eating, and drinking coffee or alcohol) or experiences (e.g., feeling stressed or unhappy) that they associated with smoking. The smoking-associated activities (e.g., eating) were dispersed throughout the entire day. In effect, they had no reprieve from smoking because it was incorporated into every nook and cranny of their lives as a "routine" or "habit". As illustrated in the following quote by Jessica, smoking engulfed their lives to such a degree that it was taken-for-granted: "My parents smoke. All my friends smoke. Everybody smokes. I smoked. I didn’t think it was a big deal.” Brittany also explained:

I never really thought about quitting smoking ...until like now that I'm pregnant and before it never even crossed my mind to even consider quitting.... You're so used to it and it just goes hand-in-hand like with everything you do.... It's just like it's second nature.

Obtaining Salubrious Effects from Smoking. The meaning of smoking to the pregnant women in this study was embedded within their stories. Lurking just below the surface of their words was the idea that smoking was paradoxically providing the women with immediate health-related benefits as it threatened to rob them of their long-term health. The women all acknowledged that ultimately smoking can be detrimental to health and it is lethal. For instance, when her family doctor questioned her about being aware that smoking is "venom," Stephanie replied, "Yes, yes, I'm not an idiot. I've read the cigarette packs and how it's going to kill me." However, as voiced by Ashley, the women did not sense any immediate danger to their health:

Well, I guess in the long-term [quitting affects] my health. I mean like it cuts out the risk of possible health problems in the future.... So it just basically gives me more of a positive chance not to contract like any cancerous problems when I become 50, or 60 , or 40 for that matter.... [Quitting gives] that possibility of a healthier future.

For the time being, smoking had therapeutic qualities and promoted a sense of well-being. All of the women used smoking as an escape from either stress or boredom and, from their perspective, they attained emotional 
stability by smoking regularly. Let us listen to Amanda as she referred to these points:

I don't think it's healthy in the long run for me.... It's just if I don't have a cigarette or if I have no cigarettes around me, I kind of go crazy.... When I tend to smoke more often or, you know, more of a constant kind of thing is when I'm stressed ...something kind of just patters me here in ...my head. I just feel like smoking would calm me for some reason and I just kind of go with it.

In the following passages, Ashley exposed other alleged health-enhancing or maintaining effects of smoking:

[Smoking cigarettes] was a really big help with like weight loss because it ...kills your craving for hunger and it was ...causing health like, you know, positive things.

The rest of my friends, like they're fine if I have a smoke because they don't want ...my blood pressure go up and have me end up in the hospital because I do have high blood pressure.

After a meal I still have to have a smoke because you're just so full and having a smoke just relieves so much like fullness in your stomach and just makes you feel ...like everything is properly going.

In telling their insightful stories, women in the study couched smoking in other ways, which also signified that the meaning of smoking went beyond smoking as a coping strategy. Besides referring to smoking as "your little friend," ironically, it was also described as "your fresh air" as though it should fall under the rubric of the necessities of life. Along the same lines, in the excerpt that follows, Stephanie replaces sustenance from food with cigarettes: "My breakfast was coffee and [a] cigarette and my lunch was coffee and [a] cigarette."

\subsection{Suddenly Finding Myself on a Moral Low Road}

The theme of suddenly finding myself on a moral low road derived from four subthemes: (a) becoming unexpectedly pregnant; (b) smoking on autopilot; (c) being subjected to judgment and condemnation; and (d) suffering emotionally.

Becoming Unexpectedly Pregnant. Against the backdrop of a smoking world all of the women became unexpectedly pregnant. A couple of participants had previously speculated about starting a family. Nevertheless, the timing of their pregnancies was not anticipated and they were caught off guard by their pregnancies along with the other women. The unexpected nature of their pregnancies was captured by Amanda, for example, in her recollection of events: "Well, I didn't plan on becoming pregnant... When I found out I was pregnant, it was definitely a shock."

Smoking on Autopilot. Despite knowledge of their pregnancies, the women carried on smoking as usual because it was "second nature" to them. Stephanie shared, "So I was only 4 weeks along when I found out [I was pregnant] and ...it didn’t sink in. Nothing had sunk in. I was still smoking.” The amount of time they smoked on autopilot varied among the women. As expressed by Jennifer, it took a wake-up call to snap them out of this mode of being:

If it wasn't for my husband, I'd still be smoking while I'm pregnant.... One day, he actually took ...my money out of my hand plus my debit [card and] ...hid it from me for 4 days. He said, "You ain't buying a pack of smokes. I'm not letting ya." ...He made me, he said, "Sit down and realize." I actually sat in the chair and screeched and balled I wanted a pack of smokes that bad.... That's what motivated me to quit smoking ...and that's what made me wake up and realize. He said, "Look, there's a baby inside of you that wants to grow ...[and] see this world."

Being Subjected to Judgment and Condemnation. All of the women in the study linked smoking in pregnancy with judgment and condemnation. For several of the women, the wake-up call during their smoking on autopilot came in the form of judgment and condemnation from others. At that time, the women entered what Heidegger [38] referred to as an "unready-to-hand" mode of engaging in the world (p. 103). Smoking as a taken-for-granted way of coping in the world suddenly became inappropriate. This drove future smoking in pregnancy underground, whereby the women would only smoke around a small inner circle of family members and/or friends.

When I was having my smoke, it actually kind of turned my stomach to have it because I could see her. She was there staring at me and I felt like she was judging me for having the smoke. Like, I shouldn't be doing 
it.... [and] I was like, "Yeah, this has got to stop. I can’t smoke in front of people.” (Ashley)

No one wants to see the big pregnant woman outside smoking cigarettes. I mean people judge you.... [My friend] stopped smoking at work because she was like, "People are hating me down there! ...I feel like I'm going to be lynched.... Smokers are staring at me like I'm the devil!” (Stephanie)

Suffering Emotionally. As depicted in the following account by Nicole, women in the study also harboured feelings of anxiety and guilt on account of smoking in pregnancy: "I really wish I could [quit] now. It stresses me out ... [and] a major thing too is I feel really guilty when I smoke.” In the turmoil of feeling a strong desire to smoke due to their addiction, yet feeling a tremendous sense of guilt over the behavior, the women naturally used defense mechanisms in response to their anxiety. Nicole was well aware that she used "excuses" to "defend" her smoking:

I use [excuses] to ...defend my smoking. I know a lot of pregnant women in ...my baby group [Healthy Baby Club] and all of them smoke. So I say to myself, "Oh well, everybody else smokes and they're pregnant.... Why can't I? Like everyone else is doing it so it's not so bad.” ... Excuses definitely play a role in my smoking. I have a lot of excuses.... I also say, "I've come so far with all this [drug] addiction now and I'm doing so well with that. What's a cigarette?” ...I end up ...tricking myself.... Another excuse [is] "Well, if I've been smoking all this time pregnant now, like maybe the baby is going through some type of withdrawal from ...not having a cigarette.”

\subsection{Navigating My Own Way to a High Road}

The theme of navigating my own way to a high road stemmed from three subthemes: (a) being left to my own devices; (b) encountering roadblocks to quitting; and (c) aiming for a high road by cutting down or quitting.

Being Left to my Own Devices. The women were dealing with an unexpected pregnancy and they were attempting day-by-day to cut down or quit smoking, which they said was "really hard" and "difficult." In spite of this situation, a predominantly lonely picture emerged from their narratives. While some of the women spoke about a supportive partner or family member, they were basically on their own to figure out how to cut down, quit, and/or stay quit. Ashley observed, "No one really talks about it 'cause it's actually so frowned upon." A sense of being abandoned by the health care professionals in their lives permeated their accounts. Sarah brought this to the fore when she said, "All ... [my doctor] did was give me a big lecture and send me on my way."

Encountering Roadblocks to Quitting. All of the women in this study faced some form of a roadblock or barrier to quitting, but those who quit smoking managed to find a way around roadblocks and avoided others. In Jennifer's situation, a roadblock she encountered came in the form of misinformation from a health care provider:

[The Public Health Nurse] said to me, "You shouldn't have stopped [smoking] when you did.... Well, you were 2 months when you found out right?" I was like, "Yup." She said, "You should have kept on going. The baby was already starting to get immune to the smoke."

According to Jennifer, she would have heeded the nurse's advice and would not have quit smoking, if she had not already done so.

Aiming for a High Road by Cutting Down or Quitting. In the face of tremendous external and internal pressure to change their smoking behaviors, three of the eight pregnant women quit, whereas the remaining women attempted to cut back on their smoking, with varying levels of success. The belief that cutting down was as good as, or even better than, quitting flourished among the women. Even women who quit smoking had heard this myth and wondered about its accuracy. All of the women strived for a moral high ground in their own way by cutting down or quitting. Jessica illustrated how quitting was the "right" thing for her to do: "So I just stopped smoking and my boyfriend hated it. He told me I might as well get an abortion if I'm gonna be smoking. He said, 'Cause ...[smoking in pregnancy is] not right to do.'” In contrast, Ashley got the message that cutting down was acceptable:

[My friend] said, “I know you're not gonna quit ...but if you can cut down to one or two a day then [that's good, but] ...if I ever see you with alcohol in your hand, oh buddy, I'll kick your ass! Or if I ever see you with any drugs, ...I'll kick your ass!” ...but she’s fine with the smoking, as long as I don't do anything else. 


\subsection{Not Preparing for Postpartum Smoking Pitfalls}

The fourth and last theme of not preparing for postpartum smoking pitfalls consisted of two subthemes: (a) being informed about postpartum smoking pitfalls; and (b) taking a wait-and-see approach.

Being Informed About Postpartum Smoking Pitfalls. All of the women, including those that had quit, were informed about some problems and dangers with postpartum smoking. For example, participants heard and knew about the hazards of second- and third-hand smoke. However, given that the pregnant women in this study were managing an unexpected pregnancy and their addiction to smoking on a day-to-day basis, they were caught up in the immediacy of their lives and they were not focused on the postpartum period. When prompted to think about this time, they spoke about pitfalls of postpartum smoking. Nicole's comments are a case in point:

I don't want ....any breathing problems because I want to be able to play [and] run with my baby ...I don't want to get cancer 'cause I don't wanna die and leave my baby here alone, stranded.... I [want] ...to stop ...because I don't want my child to smoke. I don't want him to see me smoke and think that it's okay.... I don't want my child to smell like smoke. I don't want to have to take smoke breaks while I'm trying to take care of my child.... I want my breast milk to be ...healthy.

Taking a Wait-And-See Approach. As exemplified by Jennifer's statement that follows, the women's decisions about smoking postpartum were left up in the air: "We'll see how it goes after the baby's born and if it goes good, I might actually stay quit, but if it goes the total opposite way, I may pick it up.” Although they knew about postpartum smoking pitfalls, none of the women made concrete plans or prepared to either quit or stay quit following the birth of their child. In effect, they were saying they would "cross that bridge when they came to it."

\section{Discussion}

The women's stories in this study corroborated and expanded on themes emanating from other qualitative inquiries in this area of research. In particular, women in other studies also reported feeling guilty and ashamed about smoking cigarettes while they were pregnant and hiding their gestational smoking from others due to the stigma associated with the behavior [17] [23] [25] [26]. As pointed out in this study and Edwards and Sims-Jones’ [25] research, pregnant women who smoke are demonized in our society. Smoking in pregnancy runs counter to the social construction of the "good" mother as a selfless nurturer [23] [39]. In light of the emotional suffering that accompanied the experience of smoking in pregnancy, health care guidelines, interventions, and resources aimed at helping pregnant women who smoke need to incorporate a nonjudgmental, supportive approach. Furthermore, given the stigma surrounding the experience, which drove smoking underground and isolated the women, nurses, health care professionals, and resources about smoking during pregnancy need to convey the message that the women are not alone. For instance, before the provision of statistics on gestational smoking in the recruitment pamphlet for this research, we stated, "If you smoke now or have smoked during your pregnancy, you are not alone.” Feedback from the participants in this study suggested that this opening statement facilitated the women disclosing their smoking status and coming forward to participate in the study.

This study adds to the existing body of knowledge on the experience of smoking in pregnancy by elucidating the participants' situatedness in the world. It was evident in their stories that they lived in a smoking world and the pregnant women who continued to smoke relied heavily on smoking to cope and survive in this world. While other researchers of qualitative studies on smoking in pregnancy have uncovered that smoking is an important means of coping with stress [16]-[18] [22] [25], participants in this study revealed that smoking means more than a coping strategy. The women believed that smoking confers health benefits and cigarettes even had a connection with necessities of life (i.e., air and food). Not only did smoking provide personal health benefits, but also the women heard from others that smoking in smaller amounts was as good as, or even better than, quitting for the baby's well-being. Recent research and commentary show that nurses and other health care professionals cannot afford to rest on their laurels and let circulating myths about smoking flourish. Ribisl and Jo [40], for example, noted that tobacco control is losing ground in the era of the web, which is a very fertile breeding ground for pro-tobacco content.

The ideas that smoking tobacco has healthful side effects and is related to necessities of life are actually in keeping with historical views of tobacco. Historically, tobacco was an important bridge between the mortal and spiritual realms and in South and North American tribes, tobacco was used by shamans to heal, cleanse, and 
even revive the dead [41] [42]. Tobacco smoke was food for the Gods and, in return, the Gods brought good fortune and protected the person's life and health [42]. The word smoke derives from the Old English verb smocian meaning "to drive out or away or into the open by means of smoke" [43]. From the early 15th century, the Spanish and Italian words tabaco and tabacco referred to medicinal herbs [43].

According to the women's narratives in this study, the health care professionals they interacted with played a role in the perpetuation of misinformation. Allegedly, along with providing erroneous and potentially harmful information in one instance (see the quote from Jennifer under the subtheme encountering roadblocks to quitting), the women were essentially left to their own devices in trying to deal with smoking during pregnancy. Pregnant women in other studies have complained about a lack of sufficient smoking cessation help and advice from their health care providers [14] [20]-[22] [24]. It is imperative that nurses and other health care professionals remain current on smoking cessation clinical practice guidelines that pertain to pregnant and breastfeeding women. By doing so, health care professionals can provide accurate information and ongoing smoking cessation support to these women. Pregnant women who smoke should also be referred to other professional smoking cessation services, such as the Canadian Cancer Society Smokers' Helpline. The focus of gestational smoking reduction interventions should include women's health and decrease the stigma associated with the behavior [44] [45]. Also, as tobacco use plays a critical role in couple relationships [46] forming a potential source of conflict during pregnancy [47] and partner smoking is linked with gestational smoking [29], it is of the utmost importance for nurses and other health care professionals to have separate smoking cessation interventions for expectant and new fathers [48].

We endorse a multi-pronged approach to smoking cessation that includes a traditional method of delivery by health care professionals, as well as a train-the-trainer model of delivery. Training lay volunteers, who have first-hand knowledge of the experience of smoking in pregnancy, to deliver health education in this area might be well-received. Researchers have indicated that pregnant smokers value smoking cessation advice from other pregnant women who smoked in the past [19]. Moreover, as an unexpected pregnancy and smoking social networks helped set the stage for gestational smoking in this study, nurses and other health care professionals need to move further upstream in their smoking prevention and cessation strategies to target child-bearing age women and men. Such strategies should take advantage of modern communication platforms like Facebook and YouTube to reach this young audience. However, there is some research evidence suggesting that scare tactics, which are the mainstay of many anti-tobacco campaigns [49], should be used judiciously with this age group. Currently, psychological researchers tell us that cigarette warning messages related to death backfire and have the ironic and unintended effect of producing more positive attitudes toward smoking in younger age groups, who are more likely to base their self-esteem on smoking [50].

The findings generated from this study also provide new insights into the perceptions of postpartum smoking and associated behaviors among women who smoked in pregnancy. The participants in this study took a wait-and-see approach to postpartum smoking, although they knew about problems and dangers with smoking following the baby's birth. This wait-and-see approach amounted to a missed opportunity to have supports in place for quitting or staying quit during the postpartum period. This is critical because pregnant women who quit often resume smoking postpartum [45]. The period of transition to motherhood, in and of itself, is also recognized as a potentially stressful life event [51] and the women clearly used smoking as a coping mechanism. We strongly recommend that nurses and other health care professionals provide anticipatory guidance and help women to prepare for and meet the challenges of quitting and staying quit during this vulnerable time.

The findings of this study should be interpreted with some caution. The participants in this study were self-selected and it is possible that any pregnant woman who knew about the study, but chose not to participate might have had different experiences of smoking in pregnancy. In addition, the study findings were based on a single interview with each participant. Although we had rich data and the participants were encouraged to reflect on their experiences and possible themes during the interview, it is conceivable that further interviews might have produced other findings. Nevertheless, when it comes to a phenomenological hermeneutic interpretation of an experience, as Gadamer [52] reminded us, "It would be a poor hermeneuticist who thought he could have, or had to have, the last word" about it (p. 581). On a final note, we could not tap into the experience for Aboriginal women, as all of our participants were White. Further research is needed to fill this void in the literature.

\section{Conclusion}

This study contributes to the small body of research on the whole experience of gestational smoking. All of our 
participants lived in a smoking world and smoking completely infiltrated and was firmly entrenched in their everyday lives. The findings revealed that smoking in pregnancy meant more than a coping strategy for the women in this study. Smoking was a means of attaining health and wellness in the here and now. Smoking had immediate health benefits and they needed it to function and live in their lifeworld. With a better understanding of what smoking means to pregnant women who smoke, nurses and other health care professionals need to collaborate with these women, who feel abandoned and demonized. Using holistic smoking cessation approaches with life-altering solutions based on up-to-date research and clinical best practice guidelines, health care professionals can help these women forge a new and lifelong way to health and wellness.

\section{Acknowledgements}

The authors acknowledge receipt of funding for this study from the Canadian Action Network for the Advancement, Dissemination, and Adoption of Practice-informed Tobacco Treatment (CAN-ADAPTT), Toronto, Canada.

\section{References}

[1] Coleman, T., Chamberlain, C., Cooper, S. and Leonardi-Bee, J. (2011) Efficacy and Safety of Nicotine Replacement Therapy for Smoking Cessation in Pregnancy: Systematic Review and Meta-Analysis. Addiction, 106, 52-61. http://dx.doi.org/10.1111/j.1360-0443.2010.03179.x

[2] Durmus, B., Kruithof, C.J., Gillman, M.H., et al. (2011) Parental Smoking during Pregnancy, Early Growth, and Risk of Obesity in Preschool Children: The Generation R Study. The American Journal of Clinical Nutrition, 94, 164-171. http://dx.doi.org/10.3945/ajcn.110.009225

[3] Bjerg, A., Hedman, L., Perzanowski, M., Lundbäck, B. and Rönmark, E. (2011) A Strong Synergism of Low Birth Weight and Prenatal Smoking on Asthma in Schoolchildren. Pediatrics, 127, e905-e912. http://dx.doi.org/10.1542/peds.2010-2850

[4] Karmaus, W., Dobai, A.L., Ogbuanu, I., Arshard, S.H., Matthews, S. and Ewart, S. (2008) Long-Term Effects of Breastfeeding, Maternal Smoking during Pregnancy, and Recurrent Lower Respiratory Tract Infections on Asthma in Children. Journal of Asthma, 45, 688-695. http://dx.doi.org/10.1080/02770900802178306

[5] Håberg, S.E., Bentdal, Y.E., London, S.J., Kvaerner, K.J., Nystad, W. and Nafstad, P. (2010) Prenatal and Postnatal Parental Smoking and Acute Otitis Media in Early Childhood. Acta Paediatrica, 99, 99-105. http://dx.doi.org/10.1111/j.1651-2227.2009.01506.x.

[6] Murin, S., Rafii, R. and Bilello, K. (2011) Smoking and Smoking Cessation in Pregnancy. Clinics in Chest Medicine, 32, 75-91. http://dx.doi.org/10.1016/j.ccm.2010.11.004

[7] Nichter, M., Greaves, L., Bloch, M., et al. (2010) Tobacco Use and Secondhand Smoke Exposure during Pregnancy in Low- and Middle-Income Countries: The Need for Social and Cultural Research. Acta Obstetriciaet Gynecologica Scandinavica, 89, 465-477.http://dx.doi.org/10.3109/00016341003592552

[8] Public Health Agency of Canada (2009) What Mothers Say: The Canadian Maternity Experiences Survey. Public Health Agency of Canada, Ottawa. http://www.phac-aspc.gc.ca/rhs-ssg/survey-eng.php

[9] Heaman, M.I. and Chalmers, K. (2005) Prevalence and Correlates of Smoking during Pregnancy: A Comparison of Aboriginal and Non-Aboriginal Women in Manitoba. Birth, 32, 299-305. http://dx.doi.org/10.1111/j.0730-7659.2005.00387.x

[10] Muckle, G., Laflamme, D., Gagnon, J., Boucher, O., Jacobson, J.L. and Jacobson, S.W. (2011) Alcohol, Smoking, and Drug Use among Inuit Women of Childbearing Age during Pregnancy and the Risk to Children. Alcoholism: Clinical and Experimental Research, 35, 1081-1091.http://dx.doi.org/10.1111/j.1530-0277.2011.01441.x

[11] Plaziac, C. and Hamel, D. (2007) Qanuippitaa? How Are We? Institut national de santé publique du Québec, Nunavik Regional Board of Health and Social Services, Quebec City. http://www.inspq.qc.ca/pdf/publications/667_esi_tobacco.pdf

[12] Dietz, P.M., Homa, D., England, L.J., Burley, K., Tong, V.T., Dube, S.R. and Bernert, J.T. (2011) Estimates of Nondisclosure of Cigarette Smoking among Pregnant and Nonpregnant Women of Reproductive Age in the United States. American Journal of Epidemiology, 173, 355-359. http://dx.doi.org/10.1093/aje/kwq381

[13] Graham, H. (1976) Smoking in Pregnancy: The Attitudes of Expectant Mothers. Social Science \& Medicine, 10, 399405. http://dx.doi.org/10.1016/0037-7856(76)90097-4

[14] Maclaine, K. and Macleod Clark, J. (1991) Women’s Reasons for Smoking in Pregnancy. Nursing Times, 87, 39-42.

[15] Lawson, E.J. (2003) The Role of Smoking in the Lives of Low-Income Pregnant Adolescents: A Field Study. Adolescence, 29, 61-79. 
[16] Dunn, C.L., Pirie, P.L. and Lando, H.A. (1998) Attitudes and Perceptions Related to Smoking among Pregnant and Postpartum Women in a Low-Income, Multiethnic Setting. American Journal of Health Promotion, 12, 267-274. http://dx.doi.org/10.4278/0890-1171-12.4.267

[17] Nichter, M., Nichter, M., Muramoto, M., Adrian, S., Goldade, K., Tesler, L. and Thompson, J. (2007) Smoking among Low-Income Pregnant Women: An Ethnographic Analysis. Health Education \& Behavior, 34, 748-764. http://dx.doi.org/10.1177/1090198106290397

[18] Pletsch, P.K., Morgan, S. and Pieper, A.F. (2003) Context and Beliefs about Smoking and Smoking Cessation. The American Journal of Maternal Child Nursing, 28, 320-325. http://dx.doi.org/10.1097/00005721-200309000-00012

[19] Bull, L., Burke, R., Walsh, S. and Whitehead, E. (2008) The Perceived Effectiveness of Smoking Cessation Interventions Aimed at Pregnant Women: A Qualitative Study of Smokers, Former Smokers and Non-Smokers. Journal of Neonatal Nursing, 14, 72-78. http://dx.doi.org/10.1016/j.jnn.2007.12.010

[20] Haugland, S., Haug, K. and Wold, B. (1996) The Pregnant Smoker’s Experience of Ante-Natal Care: Results from a Qualitative Study. Scandinavian Journal of Primary Health Care, 14, 216-222. http://dx.doi.org/10.3109/02813439608997088

[21] McCurry, N., Thompson, K., Parahoo, K., O’Doherty, E. and Doherty, A.M. (2002) Pregnant Women’s Perception of the Implementation of Smoking Cessation Advice. Health Education Journal, 61, 20-31. http://dx.doi.org/10.1177/001789690206100103

[22] Haslam, C. and Draper, E.S. (2001) A Qualitative Study of Smoking during Pregnancy. Psychology, Health \& Medicine, 6, 95-99. http://dx.doi.org/10.1080/713690228

[23] Wigginton, B. and Lee, C. (2012) A Story of Stigma: Australian Women's Accounts of Smoking during Pregnancy. Critical Public Health, 23, 466-481. http://dx.doi.org/10.1080/09581596.2012.753408

[24] Lendahls, L., Öhman, L., Liljestrand, J. and Håkansson, A. (2002) Women’s Experiences of Smoking during and after Pregnancy as Ascertained Two to Three Years after Birth. Midwifery, 18, 214-222.

http://dx.doi.org/10.1054/midw.2002.0312

[25] Edwards, N. and Sims-Jones, N. (1998) Smoking and Smoking Relapse during Pregnancy and Postpartum: Results of a Qualitative Study. Birth, 25, 94-100. http://dx.doi.org/10.1046/j.1523-536x.1998.00094.x

[26] Abrahamsson, A., Springett, J., Karlsson, L. and Ottosson, T. (2005) Making Sense of the Challenge of Smoking Cessation during Pregnancy: A Phenomenographic Approach. Health Education Research, 20, 367-378. http://dx.doi.org/10.1093/her/cyg127

[27] Van Manen, M. (1990) Researching Lived Experience: Human Science for an Action Sensitive Pedagogy. Althouse, London.

[28] Bergum, V. (1991) Being a Phenomenological Researcher. In: Morse, J., Ed., Qualitative Nursing Research: A Contemporary Dialogue, Sage, Newbury Park, 43-57.

[29] Al-Sahab, B., Saqib, M., Hauser, G. and Tamim, H. (2010) Prevalence of Smoking during Pregnancy and Associated Risk Factors among Canadian Women: A National Study. BMC Pregnancy and Childbirth, 10, 24. http://dx.doi.org/10.1186/1471-2393-10-24

[30] First Nations Information Governance Centre (2012) First Nations Regional Health Survey 2008/2010. First Nations Information Governance Centre, Ottawa. http://fnigc.ca/sites/default/files/RHS_Phase_II___Key_Findings.pdf

[31] Newfoundland and Labrador Provincial Perinatal Program (2008) Newfoundland and Labrador Provincial Healthy Baby Club Report-April 2001 to March 2006. Newfoundland and Labrador Provincial Perinatal Program, St. John’s.

[32] Young, K. and Chatwood, S. (2011) Environmental Scan of First Nations, Inuit, and Métis Population Health Surveys. The Canadian Partnership against Cancer, Toronto. http://www.cancerview.ca/idc/groups/public/documents/webcontent/fnim_population_health_suv.pdf

[33] Canadian Broadcasting Corporation (2013) Strategy Launched by Anti-Smoking Group. http://www.cbc.ca/news/canada/newfoundland-labrador/story/2013/02/26/nl-anti-smoking-plan-launched-226.html

[34] Morse, J.M. and Field, P.A. (1995) Qualitative Research Methods for Health Professionals. Sage, London.

[35] Kvale, S. (1983) The Qualitative Research Interview: A Phenomenological and a Hermeneutical Mode of Understanding. Journal of Phenomenological Psychology, 14, 171-196. http://dx.doi.org/10.1163/156916283X00090

[36] Meadows, L.M. and Morse, J.M. (2001) Constructing Evidence within the Qualitative Project. In: Morse, J.M., Swanson, J.M. and Kuzel, A.J., Eds., The Nature of Qualitative Evidence, Sage, Thousand Oaks, 188-201.

[37] Morse, J.M., Barrett, M., Mayan, M., Olson, K. and Spiers, J. (2002) Verification Strategies for Establishing Reliability and Validity in Qualitative Research. International Journal of Qualitative Methods, 1, 13-22.

http://ejournals.library.ualberta.ca/index.php/IJQM/index 
[38] Heidegger, M. (1962) Being and Time. Harper \& Row, New York.

[39] Bottorff, J.L., Johnson, J.L., Irwin, L.G. and Ratner, P.A. (2000) Narratives of Smoking Relapse: The Stories of Postpartum Women. Research in Nursing \& Health, 23, 126-134. http://dx.doi.org/10.1002/(SICI)1098-240X(200004)23:2<126::AID-NUR5>3.0.CO;2-2

[40] Ribisl, K.M. and Jo, C. (2012) Tobacco Control Is Losing Ground in the Web 2.0 Era: Invited Commentary. Tobacco Control, 21, 145-146. http://dx.doi.org/10.1136/tobaccocontrol-2011-050360

[41] Robicsek, F. (1978) The Smoking Gods: Tobacco in Maya Art, History, and Religion. University of Oklahoma Press, Norman.

[42] Wilbert, J. (1987) Tobacco and Shamanism in South America. Yale University Press, New Haven.

[43] Harper, D. (2013) The Online Etymology Dictionary. http://www.etymonline.com/index.php?allowed_in_frame=0\&search=smoking\&searchmode=none

[44] Bottorff, J.L., Kalaw, C., Johnson, J.L., Stewart, M., Greaves, L. and Carey, J. (2006) Couple Dynamics during Women's Tobacco Reduction in Pregnancy and Postpartum. Nicotine \& Tobacco Research, 8, 499-509. http://dx.doi.org/10.1080/14622200600789551

[45] Greaves, L., Poole, N., Okoli, C.C.T., et al. (2011) Expecting to Quit: A Best-Practices Review of Smoking Cessation Interventions for Pregnant and Post-Partum Women. Centre of Excellence for Women's Health, Vancouver. http://www.expectingtoquit.ca/documents/expecting-to-quit-singlepages.pdf

[46] Bottorff, J.L., Kalaw, C., Johnson, J.L., Chambers, N., Stewart, M., Greaves, L. and Kelly, M. (2005) Unraveling Smoking Ties: How Tobacco Use Is Embedded in Couple Interactions. Research in Nursing \& Health, 28, 316-328. http://dx.doi.org/10.1002/nur.20085

[47] Greaves, L., Kalaw, C. and Bottorff, J.L. (2007) Case Studies of Power and Control Related to Tobacco Use during Pregnancy. Women's Health Issues, 17, 325-332. http://dx.doi.org/10.1016/j.whi.2007.06.001

[48] Bottorff, J.L., Oliffe, J., Kalaw, C., Carey, J. and Mroz, L. (2006) Men’s Constructions of Smoking in the Context of Women’s Tobacco Reduction during Pregnancy and Postpartum. Social Science \& Medicine, 62, 3096-3108. http://dx.doi.org/10.1016/j.socscimed.2005.11.058

[49] Thompson, L.E., Barnett, J.R. and Pearce, J.R. (2009) Scared Straight? Fear-Appeal Anti-Smoking Campaigns, Risk, Self-Efficacy and Addiction. Health, Risk \& Society, 11, 181-196. http://dx.doi.org/10.1080/13698570902784281

[50] Hansen, J., Winzeler, S. and Topolinski, S. (2010) When Death Makes You Smoke: A Terror Management Perspective on the Effectiveness of Cigarette On-Pack Warnings. Journal of Experimental Social Psychology, 46, 226-228. http://dx.doi.org/10.1016/j.jesp.2009.09.007

[51] Churchill, A.C. and Davis, C.G. (2010) Realistic Orientation and the Transition to Motherhood. Journal of Social and Clinical Psychology, 29, 39-67. http://dx.doi.org/10.1521/jscp.2010.29.1.39

[52] Gadamer, H.G. (1989) Truth and Method. Continuum, New York. 
Scientific Research Publishing (SCIRP) is one of the largest Open Access journal publishers. It is currently publishing more than 200 open access, online, peer-reviewed journals covering a wide range of academic disciplines. SCIRP serves the worldwide academic communities and contributes to the progress and application of science with its publication.

Other selected journals from SCIRP are listed as below. Submit your manuscript to us via either submit@scirp.org or Online Submission Portal.
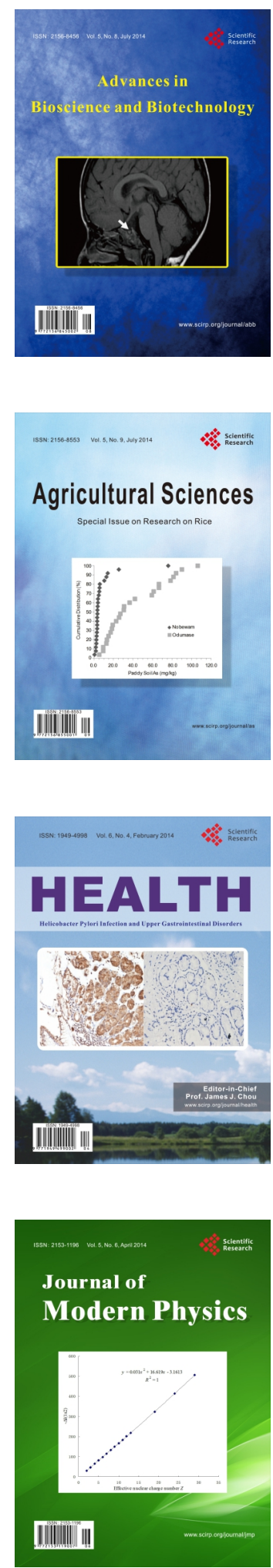
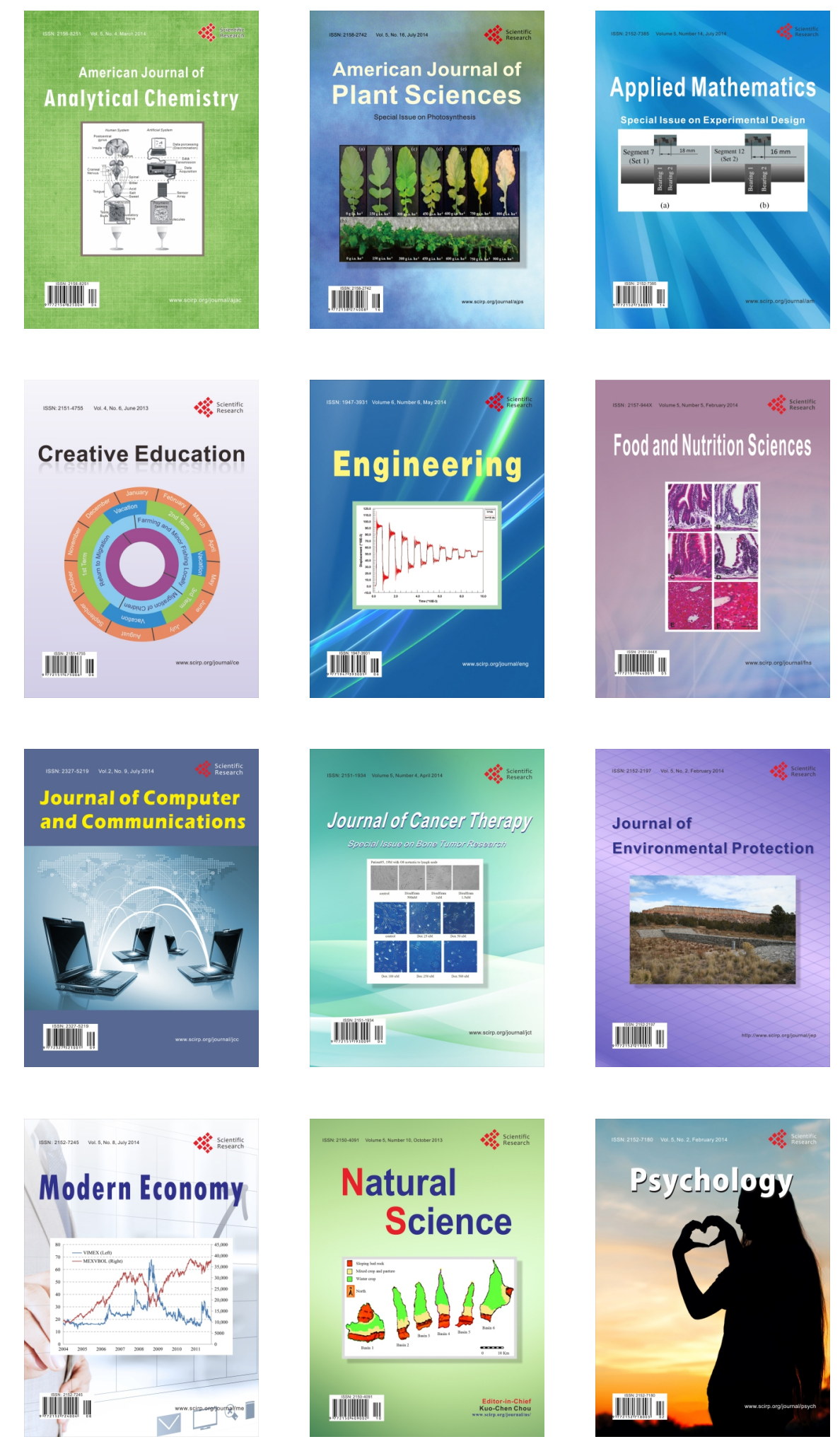